\section{Original Article}

Check for updates

\section{OPEN ACCESS}

Received: Feb 7, 2019

Accepted: Mar 31, 2019

Corresponding Author:

Ki Hwan Kim, MD

Division of Hematology and Medical Oncology,

Department of Internal Medicine, Seoul

National University Boramae Medical Center

20, Boramae-ro 5-gil, Dongjak-gu,

Seoul 07061, Korea.

Tel: +82-10-2055-6473

Fax: +82-2-870-1476

E-mail: floresta405@gamil.com

Copyright (c) 2019 by The Korean Society of Infectious Diseases and Korean Society for Antimicrobial Therapy

This is an Open Access article distributed under the terms of the Creative Commons Attribution Non-Commercial License (https:// creativecommons.org/licenses/by-nc/4.0/) which permits unrestricted non-commercial use, distribution, and reproduction in any medium, provided the original work is properly cited.

ORCID iDs

Hyerim $\mathrm{Ha}$ (D)

https://orcid.org/0000-0001-8889-144X

Ki Hwan Kim (D)

https://orcid.org/0000-0002-9001-6537

Jin Hyun Park (D)

https://orcid.org/0000-0003-1078-4139

\title{
Thromboembolism in Mycobacterium tuberculosis Infection: Analysis and Literature Review
}

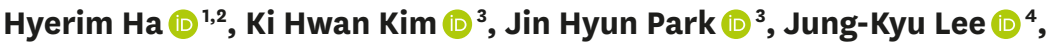 \\ Eun Young Heo (1) ${ }^{4}$, Jin-Soo Kim (10 ${ }^{3}$, Deog Kyeom Kim (10) ${ }^{4}$, In Sil Choi $\mathbb{1}^{3}$, \\ Hee Soon Chung $(\mathbb{1})^{4}$, and Hyo Jeong Lim (i) ${ }^{5}$
}

'Division of Hematology and Medical Oncology, Department of Internal medicine, Seoul National University Hospital, Seoul, Korea

${ }^{2}$ Division of Hematology and Medical Oncology, Department of Internal medicine, The Catholic University of Korea, Incheon St. Mary's Hospital, Incheon, Korea

${ }^{3}$ Division of Hematology and Medical Oncology, Department of Internal Medicine, Seoul National University Boramae Medical Center, Seoul, Korea

${ }^{4}$ Division of Pulmonology, Department of Internal Medicine, Seoul National University Boramae Medical Center, Seoul, Korea

${ }^{5}$ Department of Internal Medicine, Veterans Health Service Medical Center, Seoul, Korea
Background: Tuberculosis is associated with hypercoagulation; however, there are few reports of cases thromboembolism and tuberculosis at the same time in the real world. The purpose of this study was to report the incidence and clinical course of thromboembolism in patients diagnosed with tuberculosis.

Materials and Methods: We retrospectively analyzed the data of patients who were diagnosed with both tuberculosis and thromboembolism including pulmonary thromboembolism (PTE) or deep vein thrombosis (DVT) at Seoul National University Boramae Medical Center from January 2000 through March 2015.

Results: Among the 7905 tuberculosis patients, 49 (0.6\%) exhibited PTE, DVT, or both at or after the time of tuberculosis diagnosis. All patients treated for tuberculosis started with isoniazid, ethambutol, rifampicin, and pyrazinamide. Eight patients were switched to treatment with second-line medication because of resistance or adverse events. About half of the patients ( $\mathrm{n}=21,44.7 \%)$ had thrombosis at the time of tuberculosis diagnosis. Of 48 patients treated for thromboembolism, 36 received warfarin. A total of 20 patients improved symptom caused by thrombosis, and 10 patients were confirmed cure by image study such as computed tomography or doppler ultrasonography. Eight patients who were treated with warfarin had persistent thrombosis. Five patients (10.2\%) experienced major bleeding that required hospitalization. All of these bleeding events were associated with warfarin therapy. Conclusions: Careful attention to PTE/DVT is needed at the time of diagnosis of tuberculosis and during anti-tuberculosis therapy. Warfarin therapy administered with anti-tuberculosis medication requires frequent monitoring to prevent major bleeding.

Keywords: Tuberculosis; Thromboembolism; Pulmonary embolism; Deep vein thrombosis 


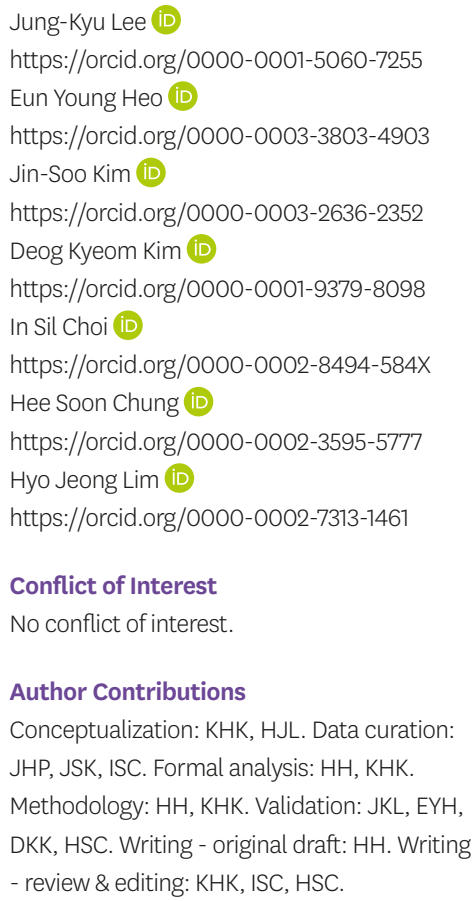

\section{INTRODUCTION}

Tuberculosis is defined as an infectious disease caused by Mycobacterium tuberculosis. It is estimated that one-third of the population worldwide is infected with the tuberculosis pathogen. In the Republic of Korea, the incidence and prevalence of tuberculosis have been reported as 143 and 97 patients per 100,000, respectively [1]. Tuberculosis leads to diverse symptoms and signs according to infected organs. The lungs are involved in approximately $90 \%$ of cases, while the gastrointestinal tract, genitourinary tract, lymph nodes, bone, muscle, and central nervous system can also be involved in so-called extrapulmonary tuberculosis. In addition, it is well known that a hypercoagulable state associated with tuberculosis may provoke thromboembolism, and this complication occurs in 0.6-1.0 of patients with tuberculosis [2]. Further, drug interactions may occur between rifampicin, the mainstay of tuberculosis treatment, and warfarin, which is widely used to manage thromboembolism [3]. However, to the best of our knowledge, few cases have been reported about thromboembolism in tuberculosis patients [4-6].

The purpose of this study was to analyze the incidence and clinical course of thromboembolism in patients with tuberculosis.

\section{MATERIALS AND METHODS}

\section{Patient population}

Patients who were diagnosed with tuberculosis at Seoul National University Boramae Medical Center from January 2000 through March 2015 were enrolled in the study. We retrospectively analyzed the data of the patients diagnosed with pulmonary thromboembolism (PTE) or deep vein thrombosis (DVT). Diagnosis of tuberculosis was confirmed by growth of $M$. tuberculosis from specimens such as sputum, fluid collected by bronchoscopy, aspirated pus, and infected-organ biopsy samples. PTE or DVT was diagnosed using imaging modalities such as computed tomography angiography and doppler ultrasonography of the extremities.

Adult patients aged 18 years or older with tuberculosis were included for analysis.

\section{Analysis}

Demographic information including gender, age at the time of diagnosis, laboratory results, and risk factors for thromboembolism was obtained by searching the electronic medical record system. The recorded laboratory results included parameters associated with coagulation state, such as protein $\mathrm{C}$, protein $\mathrm{S}$, and autoantibodies values. In addition, the treatment history for tuberculosis and PTE/DVT was obtained.

\section{Ethics statement}

The study protocol was approved by the Institutional Review Board (IRB) of the Seoul National University Boramae Medical Center (IRB no. 26-2015-101). The study was conducted in accordance with the Declaration of Helsinki.

\section{RESULTS}

Of the 7,905 patients who were diagnosed with tuberculosis, 49 (0.6\%) exhibited PTE or DVT or both at or after the time of tuberculosis diagnosis. The mean age at the time of diagnosis 
of tuberculosis was 65.5 (standard deviation, 16.3), and there were 31 male patients (63.3\%). Twelve patients had cardiovascular disease and 6 patients had malignancy or stayed under immobilization, respectively. The patients with risk factors for thromboembolism are shown in Table 1.

With regard to infection site, 45 of the 49 patients (92.9\%) exhibited pulmonary tuberculosis. Of the 49 tuberculosis patients, 47 received anti-tuberculosis medication, including 1 who underwent pneumonectomy after concluding the medical therapy. The precise tuberculosis treatment history was not available for the remaining 2 patients. The 47 treated patients all started treatment with isoniazid (H), ethambutol (E), rifampicin (R), and pyrazinamide (Z) (HERZ), but 8 of these patients were changed to a different regimen because of resistance $(\mathrm{N}=5)$ or toxicity $(\mathrm{N}=3)$. Most patients $(63.3 \%)$ treated with medication were cured.

Seventeen patients were not evaluated for the response to tuberculosis treatment; of these, 8 died during the treatment of tuberculosis and PTE/DVT (Table 1).

Among the 49 patients, 21 had PTE alone, 13 had DVT alone, and the remaining 15 had both PTE and DVT (Fig. 1). Twenty-one patients (42.3\%) exhibited PTE/DVT at the time of diagnosis with tuberculosis. In most patients $(n=36,76.6 \%)$, thromboembolism was treated with low molecular weight heparin (LMWH) followed by warfarin. Treatment with LMWH

\begin{tabular}{|c|c|}
\hline & Patients $(\mathrm{N}=49)$ \\
\hline Age (mean \pm standard deviation) & $65.5 \pm 16.3$ \\
\hline \multicolumn{2}{|l|}{ Gender } \\
\hline Male & $31(63.3 \%)$ \\
\hline Female & $18(36.7 \%)$ \\
\hline \multicolumn{2}{|l|}{ BMI $\left(\mathrm{kg} / \mathrm{m}^{2}\right)$} \\
\hline$<18.5$ & $17(34.7 \%)$ \\
\hline $18.5 \leq \mathrm{BMI}<22.9$ & $17(34.7 \%)$ \\
\hline $23 \leq \mathrm{BMI}<24.9$ & $3(6.1 \%)$ \\
\hline $25 \leq \mathrm{BMI}$ & $8(16.3 \%)$ \\
\hline Not applicable & $4(8.2 \%)$ \\
\hline \multicolumn{2}{|l|}{ Risk factor } \\
\hline Major surgery & 2 \\
\hline Immobilization & 6 \\
\hline Malignancy & 6 \\
\hline Cardiovascular disease & 12 \\
\hline Cerebrovascular disease & 4 \\
\hline Chronic alcoholics & 4 \\
\hline COPD/asthma & 5 \\
\hline No comorbidity & 8 \\
\hline \multicolumn{2}{|l|}{ Infection site } \\
\hline Pulmonary $\mathrm{Tb}$ & 45 \\
\hline Extrapulmonary Tb & 4 \\
\hline \multicolumn{2}{|l|}{ Tb treatment } \\
\hline Yes & 47 \\
\hline No & 2 \\
\hline \multicolumn{2}{|l|}{ Anti-Tb medication regimen } \\
\hline HERZ & 39 \\
\hline 2nd line therapy & 8 \\
\hline Unknown & 2 \\
\hline \multicolumn{2}{|l|}{ Response to anti-Tb medication } \\
\hline Cured & 31 \\
\hline Failed & 1 \\
\hline Not evaluated & 17 \\
\hline
\end{tabular}

BMI, body mass index; COPD, chronic obstructive pulmonary disease; Tb, tuberculosis; HERZ, isoniazid (H), ethambutol (E), rifampin (R), pyrazinamide (Z). 


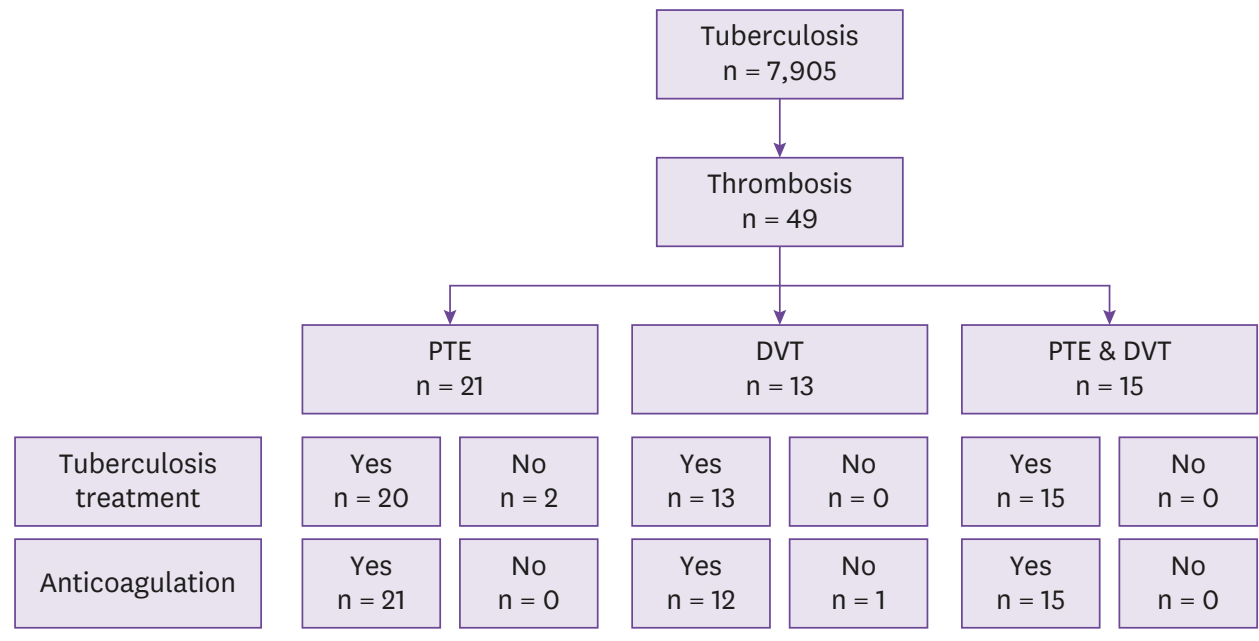

Figure 1. Pulmonary thromboembolism/deep vein thrombosis incidence of tuberculosis and treatment. The incidence of PTE/DVT and treatment pattern of tuberculosis and thromboembolism was visualized in this figure. PTE, pulmonary thromboembolism; DVT, deep vein thrombosis.

alone or novel oral anticoagulant (NOAC) agents was used in an equal but smaller number of patients. During treatment, 5 out of 8 patients were experienced major bleeding. Major bleeding was defined as bleeding requiring hospitalization. There are severe hemorrhagic manifestations such as hemoperitoneum $(\mathrm{N}=1)$, hematuria $(\mathrm{N}=1)$, hemoptysis $(\mathrm{N}=2)$, and subdural hemorrhage $(\mathrm{N}=1)$. All of these major bleeding events were associated with warfarin use, and 3 of these patients had both PTE and DVT. A total of 10 patients were confirmed cure by image study such as CT or Doppler ultrasonography and another 10

Table 2. Treatment of pulmonary thromboembolism/deep vein thrombosis

\begin{tabular}{|c|c|c|}
\hline & Patient $(\mathrm{N}=49)$ & Percent (\%) \\
\hline \multicolumn{3}{|l|}{ Location of thromboembolism } \\
\hline PTE & 21 & 42.9 \\
\hline DVT & 13 & 26.5 \\
\hline Both & 15 & 30.6 \\
\hline \multicolumn{3}{|l|}{ Diagnosis time of PTE/DVT } \\
\hline At diagnosis of $\mathrm{Tb}$ & 21 & 44.7 \\
\hline During treatment & 17 & 36.2 \\
\hline After treatment & 9 & 19.1 \\
\hline \multicolumn{3}{|l|}{ PTE/DVT treatment } \\
\hline Yes & 48 & 98.0 \\
\hline No & 1 & 2.0 \\
\hline \multicolumn{3}{|l|}{ Management of PTE/DVT } \\
\hline Warfarin & 36 & 72.5 \\
\hline LMWH & 6 & 12.2 \\
\hline NOAC & 6 & 12.2 \\
\hline Intervention + medical treatment & 6 & \\
\hline \multicolumn{3}{|l|}{ Response to treatment } \\
\hline Cure (image confirm) & 10 & 24.4 \\
\hline Clinically improved symptom & 10 & 24.4 \\
\hline Chronic state & 8 & 19.5 \\
\hline No evaluation & 13 & 31.7 \\
\hline \multicolumn{3}{|l|}{ Bleeding complication } \\
\hline None & 41 & 83.7 \\
\hline Minor bleeding & 3 & 6.1 \\
\hline Major bleeding & 5 & 10.2 \\
\hline
\end{tabular}

PTE, pulmonary thromboembolism; DVT, deep vein thrombosis; Tb, tuberculosis; LMWH, low molecular weight heparin; NOAC, novel oral anticoagulant. 
patients improved symptom clinically. Eight patients who were treated with warfarin had chronic thrombus (Table 2).

The parameters associated with coagulation state, including D-dimer, protein C, protein S, fibrinogen, antithrombin III, anti-cardiolipin antibody, lupus anticoagulant, rheumatoid factor, and anti-nuclear antibody values, were examined in the 49 patients. There was no difference among patients with PTE, DVT, and both PTE and DVT in the values of these parameters, except for rheumatoid factor (Table 3). Three out of the 8 patients with persistent thromboembolism in spite of anticoagulation treatment showed hyperfibrinogenemia before treatment.

Table 3. Factors related to coagulation by thrombosis site

\begin{tabular}{|c|c|c|c|c|}
\hline & PTE $(\mathrm{N}=21)$ & DVT $(\mathrm{N}=13)$ & Both $(\mathrm{N}=15)$ & Total $(\mathrm{N}=49)$ \\
\hline \multicolumn{5}{|l|}{ D-dimer } \\
\hline Normal & $0(0.0 \%)$ & $0(0.0 \%)$ & $0(0.0 \%)$ & $0(0.0 \%)$ \\
\hline Increased & $10(47.6 \%)$ & $5(38.5 \%)$ & $8(53.3 \%)$ & $23(46.9 \%)$ \\
\hline NA & $11(52.4 \%)$ & $8(61.5 \%)$ & $7(46.7 \%)$ & $26(53.1 \%)$ \\
\hline \multicolumn{5}{|l|}{ Platelet } \\
\hline Normal & $11(52.4 \%)$ & $12(92.3 \%)$ & $10(66.7 \%)$ & $33(67.3 \%)$ \\
\hline Increased & $7(33.3 \%)$ & $0(0.0 \%)$ & $2(13.3 \%)$ & $9(18.4 \%)$ \\
\hline NA & $3(14.3 \%)$ & $1(7.7 \%)$ & $3(20.0 \%)$ & $7(14.3 \%)$ \\
\hline \multicolumn{5}{|l|}{ Fibrinogen } \\
\hline Normal & $3(14.3 \%)$ & $5(38.5 \%)$ & $2(13.3 \%)$ & $10(20.4 \%)$ \\
\hline Increased & $7(33.3 \%)$ & $5(38.5 \%)$ & $7(46.7 \%)$ & $19(38.8 \%)$ \\
\hline NA & $11(52.4 \%)$ & $3(23.1 \%)$ & $6(40.0 \%)$ & $20(40.8 \%)$ \\
\hline \multicolumn{5}{|c|}{ Protein $\mathrm{C}$ activity } \\
\hline Decreased & $0(0.0 \%)$ & $0(0.0 \%)$ & $0(0.0 \%)$ & $0(0.0 \%)$ \\
\hline Normal & $4(19.0 \%)$ & $5(38.5 \%)$ & $5(33.3 \%)$ & $14(28.5 \%)$ \\
\hline NA & $17(81.0 \%)$ & $8(61.5 \%)$ & $10(66.7 \%)$ & $35(71.4 \%)$ \\
\hline \multicolumn{5}{|c|}{ Protein S activity } \\
\hline Decreased & $0(0.0 \%)$ & $0(0.0 \%)$ & $0(0.0 \%)$ & $0(0.0 \%)$ \\
\hline Normal & $4(19.0 \%)$ & $5(38.5 \%)$ & $5(33.3 \%)$ & $14(28.5 \%)$ \\
\hline NA & $17(81.0 \%)$ & $8(61.5 \%)$ & $10(66.7 \%)$ & $35(71.4 \%)$ \\
\hline \multicolumn{5}{|l|}{ AT III } \\
\hline Decreased & $0(0.0 \%)$ & $0(0.0 \%)$ & $0(0.0 \%)$ & $0(0.0 \%)$ \\
\hline Normal & $3(14.3 \%)$ & $6(46.2 \%)$ & $5(33.3 \%)$ & $14(28.6 \%)$ \\
\hline NA & $18(85.7 \%)$ & $7(53.8 \%)$ & $10(66.7 \%)$ & $35(71.4 \%)$ \\
\hline \multicolumn{5}{|l|}{ ACA IgM } \\
\hline Negative & $0(0.0 \%)$ & $0(0.0 \%)$ & $0(0.0 \%)$ & $0(0.0 \%)$ \\
\hline Positive & $1(4.8 \%)$ & $0(0.0 \%)$ & $1(6.7 \%)$ & $2(4.1 \%)$ \\
\hline NA & $20(95.2 \%)$ & $13(100.0 \%)$ & $14(93.3 \%)$ & 47 (95.9\%) \\
\hline \multicolumn{5}{|l|}{ LAC } \\
\hline Negative & $3(14.3 \%)$ & $1(7.7 \%)$ & $0(0.0 \%)$ & $4(8.2 \%)$ \\
\hline Positive & $0(0.0 \%)$ & $4(30.8 \%)$ & $4(26.7 \%)$ & $8(16.3 \%)$ \\
\hline NA & $18(85.7 \%)$ & $8(61.5 \%)$ & $11(73.3 \%)$ & $37(75.5 \%)$ \\
\hline \multicolumn{5}{|l|}{$\mathrm{RF}$} \\
\hline Negative & $0(0.0 \%)$ & $0(0.0 \%)$ & $0(0.0 \%)$ & $0(0.0 \%)$ \\
\hline Positive & $1(4.8 \%)$ & $6(46.2 \%)$ & $0(0.0 \%)$ & $7(14.3 \%)$ \\
\hline NA & $20(95.2 \%)$ & $7(53.8 \%)$ & $15(100.0 \%)$ & 42 (85.7\%) \\
\hline \multicolumn{5}{|l|}{ ANA } \\
\hline Negative & $0(0.0 \%)$ & $0(0.0 \%)$ & $0(0.0 \%)$ & $0(0.0 \%)$ \\
\hline Positive & $1(4.8 \%)$ & $3(23.1 \%)$ & $0(0.0 \%)$ & $4(8.2 \%)$ \\
\hline NA & $20(95.2 \%)$ & $10(76.9 \%)$ & $15(100.0 \%)$ & $45(91.8 \%)$ \\
\hline \multicolumn{5}{|l|}{ RPR } \\
\hline Negative & $1(4.8 \%)$ & $1(7.7 \%)$ & $0(0.0 \%)$ & $2(4.1 \%)$ \\
\hline Positive & $16(76.2 \%)$ & $12(92.3 \%)$ & $12(80.0 \%)$ & $40(81.6 \%)$ \\
\hline NA & $4(19.0 \%)$ & $0(0.0 \%)$ & $3(20.0 \%)$ & $7(14.3 \%)$ \\
\hline
\end{tabular}

PTE, pulmonary thromboembolism; DVT, deep vein thrombosis, NA, not available; AT III, antithrombin III; ACA, anti-cardiolipin antibody; LAC, lupus anticoagulant; RF, rheumatoid factor; ANA, anti-nuclear antibody; RPR, rapid plasma reagin test. 


\section{DISCUSSION}

This retrospective study investigated the incidence of PTE/DVT in patients diagnosed with tuberculosis at a single institution, together with the therapeutic regimens, responses to treatment, and treatment complications. This incidence of thromboembolism is higher than that in the general population of approximately $0.1 \%$ [7]. Thus, patients with tuberculosis are predisposed to the development of thromboembolism, and careful monitoring and appropriate treatment for thromboembolism are required in these patients.

Inflammation activates the coagulation cascade while decreasing the activity of the anticoagulant mechanism [8]. Inflammation in the lower respiratory tract leads to fibrin deposition - a hallmark of conditions such as pneumonia and acute respiratory distress syndrome - and resultant pulmonary and systemic thrombin generation $[9,10]$. This phenomenon is thought to occur also in tuberculosis, and analysis of laboratory test results has revealed elevated fibrinogen and fibrin degradation product levels due to impaired fibrinolysis and decreased anti-thrombin III levels in these cases. In addition, the hypercoagulable state persists for 2 weeks after the initiation of anti-tuberculosis medication and improves while continuing the treatment [11-13]. The high incidence of PTE/DVT in this study is consistent with previous studies showing that inflammation caused by tuberculosis infection causes hypercoagulability resulting in thromboembolism.

The standard treatment for tuberculosis has been 2 months of HERZ followed by 4 months of HER maintenance [14], and most patients of this study are treated initially with HERZ according to current guidelines. However, resistance has been encountered recently to certain anti-tuberculosis medications, particularly isoniazid and rifampicin. In this study, the therapeutic regimen had to be changed in 5 patients because of resistance; 3 patients showed resistance to isoniazid and 2 to isoniazid and rifampicin.

It is interesting that previous research has suggested a possible association between rifampicin use and thromboembolic complications [15]. In this study, approximately $65 \%$ of patients were diagnosed with PTE/DVT at the same time as the tuberculosis diagnosis or during treatment. Thus, thromboembolic complications may be due to tuberculosis itself or certain treatment agents including rifampicin. All treated patients took rifampicin for at least 2 weeks.

Although most patients receive warfarin to control PTE/DVT, administration of NOAC agents has been increasing recently. NOAC agents have been shown to possess similar efficacy and safety to warfarin in thromboembolism prevention and treatment [16, 17]. This shift toward NOAC use is expected to increase in tuberculosis patients with PTE/DVT because of the interaction between warfarin and rifampicin. Rifampicin acts as a non-specific inducer of hepatic cytochrome P450 and thereby affects the metabolism of multiple drugs. The metabolism of warfarin increases in the presence of rifampicin, and the dose of warfarin sometimes has to be increased to more than double the recommended level $[18,19]$. Careful monitoring of prothrombin time is necessary to monitor bleeding risk in cases of coadministration of rifampicin and warfarin. Although massive bleeding requiring hospitalization or intervention occurred in only about $10 \%$ of the patients in this study, this could be a major factor in the decision to discontinue treatment of tuberculosis or thromboembolism. All the patients with bleeding were treated with warfarin. Although warfarin is very effective for treating thromboembolism, bleeding is common and sometimes fatal. For this reason, NOAC 
agents or LMWH may be worth considering for control of PTE/DVT in patients receiving antituberculosis medication. However, caution is also needed when using NOAC agents in patients receiving anti-tuberculosis medication, because rifampicin is a CYP3A4 and P-glycoprotein/ ABCB1 inducer, and could lead to decreased serum concentration of NOAC agents such as rivaroxaban, apixaban, and dabigatran. In this study, 4 of 5 patients with major bleeding had pulmonary tuberculosis; however, serious bleeding occurred in other sites such as the abdomen and brain, and not the lung. For this reason, full physical examination should be carried out to monitor for bleeding not only in the diseased site but the whole body.

The risk factor of thromboembolism such as old age, obesity, malignancy, major surgery and bedridden state is well-known [20, 21]. In this study, we evaluate the risk factor of thromboembolism. Median age of this study was 65 years old and the patients of $83.7 \%$ had one or more risk factors. This may have affected the increased incidence of thromboembolism compared to the general population.

Our study had some limitations. The patient sample was small and comprised a singlecenter cohort. Also, this study was retrospective study not prospective observational study. Although Korea has a relatively high incidence of tuberculosis, the incidence of tuberculosis is decreasing due to improvement of hygiene environment and nutrition. Thromboembolism is reported to occur acutely within 2 weeks after the administration of the anti-Tb medication, however, long term follow-up is necessary due to it occurs chronically, also. For this reason, it was difficult to conduct prospective studies. Nonetheless, this study has value in providing well-described information about tuberculosis patients diagnosed with PTE/DVT.

In conclusion, tuberculosis patients exhibit PTE/DVT more than do the general population due to a hypercoagulable state likely associated with the tuberculosis infection. Careful monitoring for PTE/DVT is needed at the time of tuberculosis diagnosis and during antituberculosis therapy.

\section{ACKNOWLEDGMENTS}

We thank the patients included in this study.

\section{REFERENCES}

1. World Health Organization (WHO). Global tuberculosis report 2015, 20th ed. Available at: http://www. who.int/iris/handle/10665/191102. Accessed 27 March 2017.

2. Ben Amar J, Dahri B, Aouina H, Bouacha H. [Venous thromboembolism in patients with acute tuberculosis]. Rev Pneumol Clin 2015;71:327-34. PUBMED | CROSSREF

3. Lee CR, Thrasher KA. Difficulties in anticoagulation management during coadministration of warfarin and rifampin. Pharmacotherapy 2001;21:1240-6. PUBMED | CROSSREF

4. Naithani R, Agrawal N, Choudhary VP. Deep venous thrombosis associated with tuberculosis. Blood Coagul Fibrinolysis 2007;18:377-80. PUBMED | CROSSREF

5. El Fekih L, Oueslati I, Hassene H, Fenniche S, Belhabib D, Megdiche ML. Association deep veinous thrombosis with pulmonary tuberculosis. Tunis Med 2009;87:328-9. PUBMED 
6. Goncalves IM, Alves DC, Carvalho A, do Ceu Brito M, Calvario F, Duarte R. Tuberculosis and venous thromboembolism: a case series. Cases J 2009;2:9333. PUBMED | CROSSREF

7. Silverstein M, Heit JA, Mohr DN, Petterson TM, O'Fallon WM, Melton LJ 3rd. Trends in the incidence of deep vein thrombosis and pulmonary embolism: a 25-year population-based study. Arch Intern Med 1998;158:585-93. PUBMED | CROSSREF

8. Esmon CT. The interactions between inflammation and coagulation. Br J Haematol 2005;131:417-30. PUBMED | CROSSREF

9. Schultz M, Millo J, Levi M, Hack CE, Weverling GJ, Garrard CS, van der Poll T. Local activation of coagulation and inhibition of fibrinolysis in the lung during ventilator associated pneumonia. Thorax 2004;59:130-5.

PUBMED | CROSSREF

10. Günther A, Mosavi P, Heinemann S, Ruppert C, Muth H, Markart P, Grimminger F, Walmrath D, Temmesfeld-Wollbrück B, Seeger W. Alveolar fibrin formation caused by enhanced procoagulant and depressed fibrinolytic capacities in severe pneumonia. comparison with the acute respiratory distress. Am J Respir Crit Care Med 2000;161:454-62. PUBMED | CROSSREF

11. Robson S, White NW, Aronson I, Woollgar R, Goodman H, Jacobs P. Acute-phase response and the hypercoagulable state in pulmonary tuberculosis. Br J Haematol 1996;93:943-9. PUBMED | CROSSREF

12. Kager LM, Blok DC, Lede IO, Rahman W, Afroz R, Bresser P, van der Zee JS, Ghose A, Visser CE, de Jong MD, Tanck MW, Zahed AS, Alam KM, Hassan M, Hossain A, Lutter R, Veer CV, Dondorp AM, Meijers JC, van der Poll T. Pulmonary tuberculosis induces a systemic hypercoagulable state. J Infect 2015;70:323-34.

13. Turken O, Kunter E, Sezer M, Solmazgul E, Cerrahoglu K, Bozkanat E, Ozturk A, Ilvan A. Hemostatic changes in active pulmonary tuberculosis. Int J Tuberc Lung Dis 2002;6:927-32. PUBMED

14. World Health Organization (WHO). Treatment of tuberculosis: guidelines, 4th edition. Available at: http://www.who.int/iris/handle/10665/44165. Accessed 27 March 2017.

15. White NW. Venous thrombosis and rifampicin. Lancet 1989;2:434-5. PUBMED | CROSSREF

16. van Es N, Coppens M, Schulman S, Middeldorp S, Büller HR. Direct oral anticoagulants compared with vitamin $\mathrm{K}$ antagonists for acute venous thromboembolism: evidence from phase 3 trials. Blood 2014;124:1968-75.

PUBMED | CROSSREF

17. Konstantinides SV, Barco S, Lankeit M, Meyer G. Management of pulmonary embolism: an update. J Am Coll Cardiol 2016;67:976-90. PUBMED | CROSSREF

18. Lee CR, Thrasher KA. Difficulties in anticoagulation management during coadministration of warfarin and rifampin. Pharmacotherapy 2001;21:1240-6. PUBMED | CROSSREF

19. Martins MA, Reis AM, Sales MF, Nobre V, Ribeiro DD, Rocha MO, Ribeiro AL. Rifampicin-warfarin interaction leading to macroscopic hematuria: a case report and review of the literature. BMC Pharmacol Toxicol 2013;14:27. PUBMED | CROSSREF

20. Anderson FA Jr, Spencer FA. Risk factors for venous thromboembolism. Circulation 2003;107 (23 Suppl 1): I9-16. PUBMED | CROSSREF

21. Anderson FA, Wheeler HB, Goldberg RJ, Hosmer DW, Forcier A. The prevalence of risk factors for venous thromboembolism among hospital patients. Arch Intern Med 1992;152:1660-4. PUBMED | CROSSREF 